\title{
Antifouling effects of the periostracum on algal spore settlement in the mussel Mytilus edulis
}

\author{
Ji-Young Kang ${ }^{1}$, Issa Bangoura', Ji-Young Cho², Jin Joo ${ }^{3}$, Yoo Seong Choi ${ }^{4}$, Dong Soo Hwang ${ }^{5}$ and Yong-Ki Hong ${ }^{1 *}$
}

\begin{abstract}
In nature, marine mussels (Mytilus edulis) suffer less fouling colonization on the newly formed sides of their shells. Using settlement assays with algal spores of Porphyra suborbiculata, we determined that spore attachment and germination on the periostracum decreased to 36.8 and $3.3 \%$, respectively. Additionally, the spore settlement was considerably diminished by periostracum dichloromethane extracts containing $19 \%$ oleamide, a major antifouling compound. A scanning electron micrograph of the surface revealed a regular ripple structure with approximately $1.4 \mu \mathrm{m}$ between ripples. Based on these results, mussel periostraca or their associated biomimetic materials may become environmentally friendly, antifouling agents for preventing the settlement of soft foulants.
\end{abstract}

Keywords: Antifouling, Mytilus edulis, Oleamide, Periostracum

\section{Background}

Biofouling is a natural marine ecosystem process caused by the surface colonization and development of microand macrofoulers on submerged natural or artificial marine structures, and can lead to economic and environmental losses worldwide. The fouling of ship hulls and fishing nets results in major costs for the marine industry through increased maintenance and fuel requirements due to greater levels of hull drag, lost productivity due to an increased frequency of dry-docking for the removal of fouling organisms, and compliance with environmental regulations (Yebra et al. 2004). Previously utilized antifouling agents, such as the common vessel tributyltin biocidal coatings, although effective against fouling, are also toxic (Minchin et al. 1996; Atanasov et al. 2005; Sonak 2009). As a result of the negative environmental impacts associated with its toxicity, tributyltin has become the subject of a relatively recent worldwide ban by the International Maritime Organization (IMO). Due to the limitations of conventional coatings, research on biomimetic surfaces and compounds inspired by natural systems has become

\footnotetext{
* Correspondence: ykhong@pknu.ac.kr

${ }^{1}$ Department of Biotechnology, Pukyong National University, Namku, Busan 48513, Korea

Full list of author information is available at the end of the article
}

important (Scardino and de Nys 2011). Researchers have observed that some marine species, such as mussels, can resist fouling when in good physiological condition (Scardino and de Nys 2004; Bers et al. 2006). Mussels have a tough, yet pliable, proteinaceous shell covering secreted by the mantle, known as the periostracum (Harper and Skelton 1993; Scardino et al. 2003). Wahl et al. (1998) found that when the periostracum was physically removed in Mytilus edulis, they observed an increase in the settlement of barnacles and algae on the shell. Conversely, mussels with an intact periostracum showed a greater resistance to fouling pressure (Scardino et al. 2003). Several studies have reported the benefits of microtopography on mussel shells as a physical fouling deterrent (Bers and Wahl 2004; Scardino and de Nys 2004). However, the general antifouling role of the periostracum in deterring settlement of fouling organisms and its underlying mechanisms remain unclear. Therefore, we investigated chemical elements from periostracum extracts and the physical surface of the periostracum responsible for defense against algal spore settlement. Monospores of Porphyra suborbiculata, one of common wild seaweed and easily obtainable throughout the year in a laboratory scale, were conveniently used as an assay organism for spore attachent and germination. 


\section{Methods \\ Mussels}

Aquacultured $(6.5 \pm 0.4 \mathrm{~cm})$ and wild $(4.4 \pm 0.3 \mathrm{~cm})$ Mytilus edulis mussels were purchased from the Namcheon fish market and collected from the rocky intertidal area at Eegidae $\left(35^{\circ} 11^{\prime} 97^{\prime \prime} \mathrm{N}, 129^{\circ} 12^{\prime} 74^{\prime \prime} \mathrm{E}\right)$, on the east coast of Busan, Korea. For solvent extraction, shells of aquacultured mussels were gently cleaned to remove associated detritus and epibionts prior to submersion in vinegar solution.

\section{Periostracum extracts}

Whole shells were submerged in a vinegar and seawater mixture (1:2 vinegar: seawater, approximately $2 \%$ acetic acid) to aid in removing the periostracum (Grandison et al. 2011). Shells were retained in this mixture for $1 \mathrm{~d}$, after which the periostracum was peeled from the shell with forceps and stored in seawater. After rinsing with distilled water, the peeled periostraca were freeze-dried and ground to a powder by hand for 5 min using a mortar and pestle. Twenty mg of periostracum powder was extracted with each one $\mathrm{mL}$ solvent of dichloromethane, ethyl acetate, and methanol. Extraction with each solvent was repeated three times for $1 \mathrm{~h}$ using pulses of an ultrasonic water bath (low-intensity frequency of $40 \mathrm{kHz}$ ), and the extracts were then dried with nitrogen. A stock solution of each extraction was prepared by adding $1 \mathrm{~mL}$ dimethyl sulfoxide (DMSO) to each $40 \mathrm{mg}$ of dried extract. The prepared stocks were filtered through a $0.45-\mu \mathrm{m}$ syringe filter before use.

\section{GC-MS analysis}

The dichloromethane extracts of non-treated (i.e., no vinegar) periostraca were analyzed by gas chromatography-mass spectrometry (GC-MS) using a QP5050A instrument (Shimadzu, Kyoto, Japan) equipped with a flame-ionization detector and compared with spectral data from the database. Analysis was performed on an HP-5 column ( $30 \mathrm{~m} \times 0.25 \mathrm{~mm}, 0.25 \mu \mathrm{m}$; Agilent Technologies, Santa Clara, CA, USA). The temperature was initially held at $50{ }^{\circ} \mathrm{C}$ for $2 \mathrm{~min}$ and raised to $150{ }^{\circ} \mathrm{C}$ at $4{ }^{\circ} \mathrm{C} / \mathrm{min}$ and to $250{ }^{\circ} \mathrm{C}$ at $7{ }^{\circ} \mathrm{C} / \mathrm{min}$. Helium carrier gas was controlled at $0.6 \mathrm{~mL} / \mathrm{min}$ with a split ratio of $1: 50$. The mass spectrometer was operated in electronionization mode at $70 \mathrm{eV}$.

\section{Scanning electron microscopy}

The periostracum, peeled from the shell, was rinsed with distilled water and freeze-dried under vacuum before scanning electron microscopy (SEM) analysis. For SEM images, periostracum was mounted on conductive carbon tabs of a SEM post (Ted Pella, Inc., Redding, CA), sputter-coated using a Desk-II coater equipped with a gold target (Alfa Aesar, Ward Hill, MA), and imaged in a scanning-electron microscope (JSM-6700F; JEOL, Tokyo, Japan).

\section{Algal spores}

Juvenile blades of $P$. suborbiculata were collected from the rocky intertidal area at the mussel collection site. The fresh blades were rinsed, sonicated $(40 \mathrm{kHz})$ twice for $1 \mathrm{~min}$ in autoclaved seawater, and immersed in $1 \%$ Betadine solution with $2 \%$ Triton X-100 for 1 min to eliminate epiphytes (Choi et al. 2005). To liberate the monospores, blades were cultured in Provasoli-enriched seawater (PES) medium (Provasoli 1968) under a $40 \mu \mathrm{mol} / \mathrm{m}^{2} / \mathrm{s}$ light intensity (10 L:14D) at $18^{\circ} \mathrm{C}$. Monospores were then used for attachment and germination assays under the same conditions.

\section{Attachment and germination assays}

For assays of algal spore attachment, aliquots of $100 \mu \mathrm{L}$ seawater were first distributed into a 96-well plate. We added $1 \mu \mathrm{L}$ of periostracum extract $(40 \mathrm{mg} / \mathrm{ml}), 4 \mu \mathrm{L}$ PES stock, and approximately 100-200 spores to each, with the final volume being $200 \mu \mathrm{L}$. The resulting spore suspensions were placed in the dark for $1 \mathrm{~d}$ at $18{ }^{\circ} \mathrm{C}$ to allow for even settlement on the bottom. At the end of this period, nonattached spores were removed from the bottom by centrifugation in an inverted position at $1500 \times g$ for $15 \mathrm{~min}$. The number of attached spores was counted under a microscope after replacing the PES solution. Relative attachment (\%) was expressed as a percentage of the attached spores against total spores added. The reference for each test was prepared using the same procedure but with no extract. The minimum detectable inhibition of spore attachment by DMSO occurred at $0.5 \%$. Thus, the solvent extracts and reference were always added to the assay medium to provide a DMSO concentration of less than $0.5 \%$. For spore germination assays, approximately 100-200 spores were added to a $200-\mu \mathrm{L}$ aliquot of PES in a 96-well plate and placed in the dark for $1 \mathrm{~d}$ at $18{ }^{\circ} \mathrm{C}$ to allow spores to settle on the bottom. After removing the nonattached spores by centrifugation in an inverted position, a fresh $200 \mu \mathrm{L}$ of PES was added. Then, $1 \mu \mathrm{L}$ of each extract (40 mg/ml) was immediately added to each $200 \mu \mathrm{L}$ culture. The resulting germination cultures were placed at $18{ }^{\circ} \mathrm{C}$ and $80 \mu \mathrm{mol} / \mathrm{m}^{2} / \mathrm{s}$ light intensity on a $12 \mathrm{~L}: 12 \mathrm{D}$ cycle for 1 week to permit development. The number of germlings was counted under a microscope and expressed as relative germination (\%), i.e., the percentage of germinated spores to the total number of spores attached. The minimum DMSO concentration leading to detectable inhibition was $0.5 \%$. Thus the final concentration of DMSO was kept below $0.5 \%$ in all assays. 


\section{Statistical analysis}

The experiments were repeated at least three times with each independent assay. The means of each indicator were compared to the controls using Student's $t$-tests.

\section{Results and discussion}

The shells of epibenthic bivalves offer substantial space for settlement of larvae and algal spores; however, the shells of mytilids often appear less fouled than adjacent biological and nonbiological substrata, where newer margin parts generally have fewer epibionts in nature. When we divided the external surface of wild mussel shells into five sections, approximately 70 epibionts of epizoons and epiphytes were observed on the oldest umbo parts, and fewer were detected on the margin parts (Fig. 1); the new margin parts have intact surfaces to defend against fouling settlement. Aquaculture mussels generally had the same trend, even with fewer numbers of epibionts on shell surfaces. This reduced settlement may be related to the intact texture and/or fresh components of the non-damaged periostracum. When looking at fouling organisms on mussel shells, we observed that the shells of aquaculture mussels had intact periostraca while those of wild mussels were damaged. Thus, the shells of aquaculture mussels were largely unfouled compared to the shells of wild mussels. In various molluscs, a range of fouling organisms, including endolithic algae, sponges, and other invertebrates, have shown a preference for areas of the shell where the periostracum is abraded or absent, such as on older shells (Kaehler 1999). Wahl et al. (1998) found that fouling by algae and barnacles on $M$. edulis was significantly greater on areas of the shell where the periostracum had been physically removed. Overall, a strong

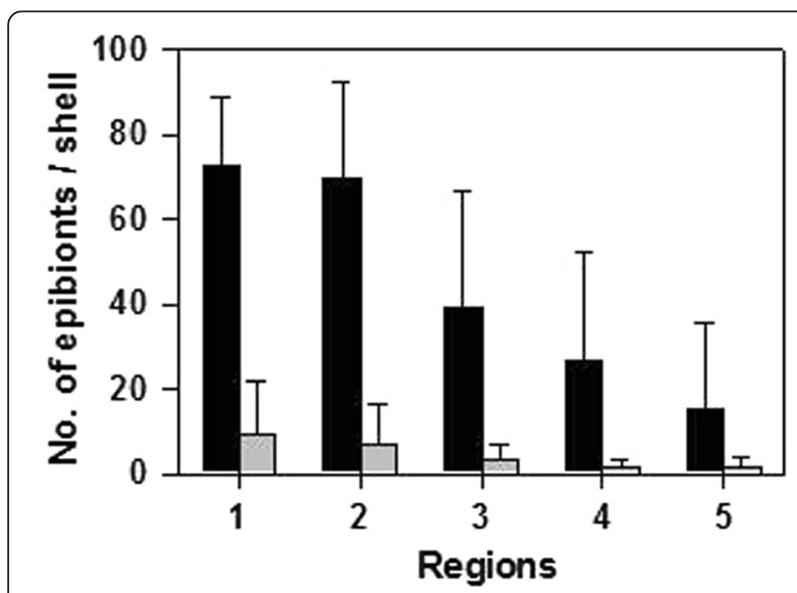

Fig. 1 Numbers of epibionts on periostraca of the wild and farmed mussel Mytilus edulis. Black and gray bars represent wild and farmed mussels, respectively. Regions are divided into five sections from the oldest umbo part (1) to the newer margin parts (5) of shells. Values are means \pm SD $(n=100)$ correlation exists between the presence of an intact periostracum and reduced fouling, which is consistent with the idea that the periostracum is used as an antifouling structure.

The aquacultured mussel shells were dipped in vinegar seawater, and the periostracum was peeled. When monospores of $P$. suborbiculata were added to the periostracum peels in PES, $36.8 \%$ of spores attached successfully, and among attached spores, only $3.3 \%$ germinated (Table 1). Thus, the periostracum showed potent anti-settlement effects on algal spores compared to the reference polystyrene material of the 24-well plate. The intact periostracum is able to resist fouling pressures via chemical and physical antifouling defense components. To investigate the potential antifouling effects of the periostracum, solvent extracts were first prepared and tested for efficacy in preventing the attachment and germination of algal spores. Three solvents, dichloromethane, ethyl acetate, and methanol, with different polarities were used to extract the soluble compounds from fresh periostraca and vinegar-treated periostricum peels. When $200 \mu \mathrm{g} / \mathrm{ml}$ of each extract was placed in the attachment and germination assay mixtures, dichloromethane extracts of both non-treated and vinegar-treated periostraca showed an attachment reduction of 31-35\% and a germination reduction of 3-5\% (Table 2). Extracts produced by the more nonpolar solvents were more effective in preventing attachment and germination, suggesting that the responsible compound also has a nonpolar lipophilic property. The chemical composition of the potent dichloromethane extract of non-treated periostraca was analyzed by GC-MS (Table 3). The major components by relative mass percentage were oleamide (19\%), an amide of the fatty acid oleic acid, and 1-tetracosanol (9\%), a fatty alcohol derived from the fatty acid lignoceric acid. One of the major compounds in the dichloromethane extract of mussel periostraca was oleamide $\left(\mathrm{C}_{18} \mathrm{H}_{35} \mathrm{NO}\right.$; CAS number 301-02-0), an endogenous amide form of oleic acid. This compound has shown antifouling effects on Ulva pertusa spore settlement and germination; i.e., it inhibited $100 \%$ settlement with $10 \mu \mathrm{g} / \mathrm{ml}$ (Cho 2012). Oleamide is also known to induce sleep in animals by

Table 1 Attachment and germination of algal spores on periostracum peels of the mussel Mytilus edulis

\begin{tabular}{lll}
\hline & Relative attachment $^{c}(\%)$ & Relative germination $^{c}(\%)$ \\
\hline $\begin{array}{l}\text { Periostracum }_{\text {peels }^{\mathrm{a}}} \\
\text { 232/629 }(36.8 \%)^{*}\end{array}$ & $10 / 299(3.3 \%)^{* *}$ \\
Reference $^{\mathrm{b}}$ & $1532 / 1823(84.0 \%)$ & $1042 / 1288(80.9 \%)$ \\
\hline
\end{tabular}

${ }^{a}$ Spores were added to the periostracum peels in the 24-well plate

${ }^{b}$ Polystyrene material of the 24 -well plate without peels was used as a reference

'Values are means \pm SD $(n \geq 4)$

${ }^{*} P<0.1,{ }^{* *} P<0.01$ 
Table 2 Effects of periostracum extracts $(200 \mu \mathrm{g} / \mathrm{mL}$ each) on the attachment and germination of Porphyra suborbiculata monospores

\begin{tabular}{|c|c|c|c|c|}
\hline Periostracum & Extracts & Yield (\%) & Relative attachment $\mathrm{a}^{\mathrm{a}}(\%)$ & Relative germination $^{\mathrm{a}}(\%)$ \\
\hline \multirow[t]{3}{*}{ Acidified outer } & Dichloromethane & 21.5 & $35 \pm 17^{* *}$ & $5.1 \pm 1.8^{* *}$ \\
\hline & Ethyl acetate & 5.0 & $41 \pm 7^{* *}$ & $8.9 \pm 2.4^{* *}$ \\
\hline & Methanol & 5.0 & $55 \pm 9^{*}$ & $10.6 \pm 5.0^{* *}$ \\
\hline \multirow[t]{3}{*}{ Acidified inner } & Dichloromethane & 37.5 & $31 \pm 7^{* *}$ & $3.5 \pm 3.2^{* *}$ \\
\hline & Ethyl acetate & 5.0 & $32 \pm 1^{* *}$ & $5.2 \pm 2.6^{* *}$ \\
\hline & Methanol & 5.0 & $34 \pm 6^{* *}$ & $10.6 \pm 2.4^{* *}$ \\
\hline \multirow[t]{3}{*}{ Fresh inner } & Dichloromethane & 0.5 & $35 \pm 5^{* *}$ & $3.4 \pm 5.4^{* *}$ \\
\hline & Ethyl acetate & 1.5 & $37 \pm 9^{* *}$ & $4.5 \pm 4.1^{* *}$ \\
\hline & Methanol & 1.0 & $47 \pm 8^{*}$ & $16.5 \pm 3.6^{* *}$ \\
\hline Reference & & & $81 \pm 7$ & $83.2 \pm 5.9$ \\
\hline
\end{tabular}

Relative activities (\%) are expressed as means \pm SD $(n \geq 3)$

${ }^{*} P<0.1,{ }^{* *} P<0.01$

interacting with multiple neurotransmitter systems (Huitron-Resendiz et al. 2001; Mendelson and Basile 2001). In an open-field test of locomotion, the $\mathrm{ED}_{50}$ (the dose causing half of the observed effect) of locomotion reduction was an injection of $17 \pm 1.5 \mathrm{mg} / \mathrm{kg}$ (Fedorova et al. 2001). Oleamide injections cause dose-dependent reductions in the time required to fall asleep, and reductions in locomotion in research animals, both with high reliability. Synthetically produced oleamide has a variety of industrial uses, including its application as a slip agent, lubricant, and corrosion inhibitor. Slip agents are used in polyethylene to bloom to the surface once the film has been produced and to reduce friction coefficients in postprocessing operations (Garrido-López et al. 2006). Briscoe et al. (1972) found that adding surface films of oleamide to a substrate reduced the friction coefficient to as low as 0.03 , compared to 0.4 for

Table 3 Profile of the major compounds in the dichloromethane extract of periostraca using GC-MS

\begin{tabular}{llc}
\hline RT (min) & Compounds & Composition $^{\text {a }}(\%)$ \\
\hline 8.3 & Nonanal & 1.49 \\
10.9 & Pelargonic acid (C7:0) & 0.32 \\
17.6 & Myristic acid (C14:0) & 0.37 \\
21.4 & Palmitic acid (C16:0) & 0.31 \\
22.8 & Phytol & 0.28 \\
23.5 & Stearic acid (C18:0) & 0.38 \\
33.3 & Oleamide & 19.00 \\
37.7 & 1-Tetracosanol & 8.89 \\
38.0 & Cholest-5-en-3-ol & 3.61 \\
40.4 & 1-Pentacosanol & 3.91 \\
- & Unknown compounds & 61.44 \\
\hline
\end{tabular}

${ }^{\mathrm{a} C o m p o s i t i o n ~ v a l u e s ~ a r e ~ p e r c e n t a g e s ~ o f ~ t h e ~ r e l a t i v e ~ p e a k ~ a r e a s ~}$ unlubricated surfaces. An organic corrosion inhibitor such as disodium oleamide sulfosuccinate can be used to control either corrosion attack at anodic sites or depolarizing reactions at cathodic sites (Brooman 2002). A second major compound found in the periostracum extract was 1-tetracosanol $\left(\mathrm{C}_{24} \mathrm{H}_{50} \mathrm{O}\right.$; CAS number 506-51-4), a fatty alcohol derived from the fatty acid lignoceric acid. Long-chain, primary alcohols are of high industrial value, mostly serving as surfactants in detergents and other cleaning products (Houston 1984). The excellent lubrication properties and stabilities of fatty alcohols make them valuable to the lubricant industry, particularly as high-performance factory machine lubricants and automobile transmission fluids. Thus, these major compounds are directly or indirectly related to the antifouling effects of mussel periostraca.

To understand physical antifouling defenses, a fresh margin part of mussel periostracum was used for scanning electron micrography (SEM). The natural surface microtopographies of the periostracum may contribute to the antifouling strategies of mussels. As shown in Fig. 2, the margin part of periostracum has a thin transparent layer. Using a scanning electron microscope at $10,000 \times$ magnification, a regular ripple structure was found on the periostracum, where regular corrugated ridges run parallel to each other and stretch across the entire shell without branching. The distance between ridges is approximately $1.4 \mu \mathrm{m}$. Periostracum microtopography is on a substantially smaller scale than the roughly $15 \mu \mathrm{m}$ diameter of the typical algal Porphyra monospore. Furthermore, intact Mytilus ripple structures are also known to reduce settlement of shellfish larvae. Previous studies have shown that intact Mytilus ripple structures significantly reduce the settlement of larvae of the barnacle Balanus amphitrite (Scardino 


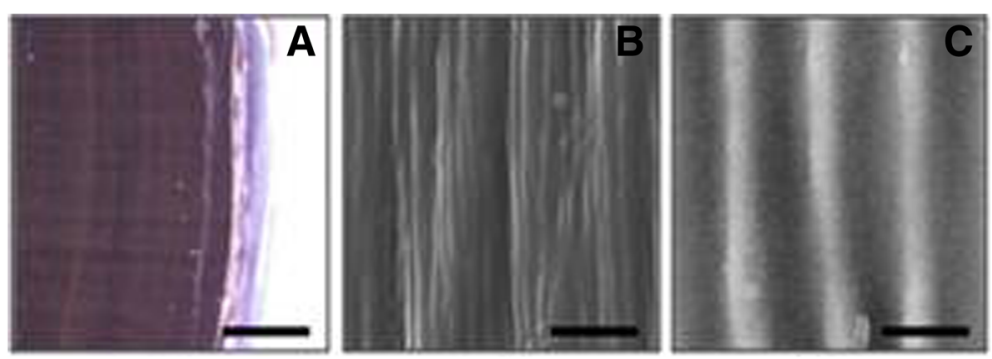

Fig. 2 Surface structure of the periostracum from Mytilus edulis. a Light micrograph of the structure (10x magnification; bar = $1 \mathrm{~mm})$. $\mathbf{b}$ Scanning

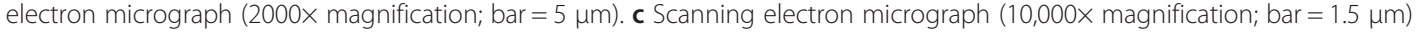

et al. 2003). Behavioral experiments show that barnacle cyprids have a higher propensity for smooth surfaces than for micro-textured surfaces. Surface textures with profile heights within a topographic range of 30-45 $\mu \mathrm{m}$ reduced settlement and recruitment by $92 \%$ compared to smooth surfaces. These repellent effects disappeared when the microtopography was destroyed by periostracum erosion (Scardino et al. 2003). Thus, marine mussels have physical defensive structures to complement their chemical antifouling defenses (Bers et al. 2006). Biogenically derived microtopographies may represent a promising nontoxic and environmentally friendly substrate, but the surface structures of biomimetic antifouling materials must parallel natural microtopographies.

\section{Conclusions}

Our research has shown that periostracum extracts display some antifouling effects, while the periostracum also physically deters the settlement of spores. These findings strengthen mimetic application claims holding that the components and surface microtopographies of $M$. edulis periostraca can be used as models for antifouling materials. Our results, periostracum composition and structure results, suggest that mussel periostraca or their associated biomimetic materials may become environmentally friendly antifouling materials preventing the attachment of diverse fouling organisms.

\section{Competing interests}

The authors declare that they have no competing interests.

\section{Authors' contributions}

JYK carried out the antifouling assay. IB carried out the collection of periostracum and in situ survey. JYC carried out the composition analysis. JJ participated in the design of the study. YSC participated in the design of the study. DSH conceived of the study and helped to draft the manuscript. YKH designed the study and completed the manuscript. All authors read and approved the final manuscript

\section{Acknowledgments}

This work was supported by a National Research Foundation of Korea grant funded by the Korean government (MEST) (NRF-M1A5A1-2011-0029963).

\section{Author details}

${ }^{1}$ Department of Biotechnology, Pukyong National University, Namku, Busan 48513, Korea. ${ }^{2}$ Department of Life Science and Biotechnology,

Soonchunhyang University, Asan 31538, Korea. ${ }^{3}$ Department of Applied Chemistry, Kyungpook National University, Bukgu, Daegu 41566, Korea. ${ }^{4}$ Department of Chemical Engineering, Chungnam National University, Yuseonggu, Daejeon 34134, Korea. ${ }^{5}$ School of Environmental Science and Engineering, Pohang University of Science \& Technology, Namgu, Pohang 37673, Korea.

Received: 9 March 2016 Accepted: 12 March 2016

Published online: 18 March 2016

\section{References}

Atanasov AG, Nashev LG, Tam S, Baker ME, Odermatt A. Organotins disrupt the $11 \beta$-hydroxysteroid dehydrogenase type 2-dependent local inactivation of glucocorticoids. Environ Health Perspect. 2005;113:1600-6.

Bers AV, Wahl M. The influence of natural surface microtopographies on fouling. Biofouling. 2004;20:43-51

Bers AV, Prendergast GS, Zurn CM, Hansson L, Head RM, Thomason JC. A comparative study of the anti-settlement properties of mytilid shells. Biol Lett. 2006;2:88-91.

Briscoe BJ, Mustafaev V, Tabor D. Lubrication of polythene by oleamide and stearamide. Wear. 1972;19:399-414.

Brooman EW. Modifying organic coatings to provide corrosion resistance part III: organic additives and conducting polymers. Met Finish. 2002;100: 104-10.

Cho JY. Antifouling activity of giffinisterone B and oleamide isolated from a filamentous bacterium Leucothrix mucor culture against Ulva pertusa. Kor J Fish Aquat Sci. 2012;45:30-4.

Choi JS, Kang SE, Cho JY, Shin HW, Hong YK. A simple screening method for anti-attachment compounds using monospores of Porphyra yezoensis Ueda. J Fish Sci Technol. 2005:8:51-5.

Fedorova I, Hashimoto H, Fecik RA, Hedrick MP, Hanus LO, Boger DL, Rice KC, Basile AS. Behavioral evidence for the interaction of oleamide with multiple neurotransmitter systems. J Pharmacol Exp Ther. 2001;299:332-42.

Garrido-López Á, Esquiu V, Tena MT. Determination of oleamide and erucamide in polyethylene films by pressurized fluid extraction and gas chromatography. J Chromatogr A. 2006;1124:51-6.

Grandison C, Scardino A, Ovenden S. An investigation of the antifouling potential of extracts of the periostracum of Mytilus sp. Defence Science and Technology Organisation, Report DSTO-TN-1017, Australia. 2011.

Harper EM, Skelton PW. A defensive value of the thickened periostracum in the Mytiloidea. Veliger. 1993;36:36-42.

Houston CA. Marketing and economics of fatty alcohols. J Am Oil Chem Soc. 1984:61:179-84.

Huitron-Resendiz S, Gombart L, Cravatt BF, Henriksen SJ. Effect of oleamide on sleep and its relationship to blood pressure, body temperature, and locomotor activity in rats. Exp Neurol. 2001;172:235-43.

Kaehler S. Incidence and distribution of phototrophic shell-degrading endoliths of the brown mussel Perna perna. Mar Biol. 1999;135:505-14.

Mendelson WB, Basile AS. The hypnotic actions of the fatty acid amide, oleamide. Neuropsychopharmacology. 2001;25:S36-9. 
Minchin D, Stroben E, Oehlmann J, Bauer B, Duggan CB, Keatinge M. Biological indicators used to map organotin contamination in Cork Harbour, Ireland. Mar Pollut Bull. 1996;32:188-95.

Provasoli L. Media and prospects for the cultivation of marine algae. In: Watanabe A, Hattori A, editors. Cultures and collections of algae. Tokyo: The Japanese Society of Plant Physiologists; 1968. p. 63-75.

Scardino AJ, de Nys R. Fouling deterrence on the bivalve shell Mytilus galloprovincialis: a physical phenomenon? Biofouling. 2004;20:249-57.

Scardino AJ, de Nys R. Biomimetic models and bioinspired surfaces for fouling control. Biofouling. 2011;27:73-86.

Scardino AJ, de Nys R, Ison O, O'Connor W, Steinberg PD. Microtopography and antifouling properties of shell surface of the bivalve molluscs Mytilis galloprovincialis and Pinctada imbricata. Biofouling. 2003;19:S221-30.

Sonak S. Implications of organotins in the marine environment and their prohibition. J Environ Manage. 2009;90:51-3.

Wahl M, Kroeger K, Lenz M. Non-toxic protection against epibiosis. Biofouling. 1998;12:205-26.

Yebra DM, Kiil S, Dam-Johansen K. Antifouling technology-past, present and future steps towards efficient and environmentally friendly antifouling coatings. Prog Org Coat. 2004;50:75-104.

Submit your next manuscript to BioMed Central and we will help you at every step:

- We accept pre-submission inquiries

- Our selector tool helps you to find the most relevant journal

- We provide round the clock customer support

- Convenient online submission

- Thorough peer review

- Inclusion in PubMed and all major indexing services

- Maximum visibility for your research

Submit your manuscript at www.biomedcentral.com/submit
Biomed Central 